\title{
On the Relationship Factor between the PV Module Temperature and the Solar Radiation on it for Various BIPV Configurations
}

\author{
S. Kaplanis* and E. Kaplani \\ Renewable Energy Systems Lab., Mechanical Engineering Dept., Technological Educational Institute of Western \\ Greece, Koukouli 26 334, Patra, Greece \\ *Correspondence: kaplanis@teipat.gr
}

\begin{abstract}
Temperatures of c-Si, pc-Si and a-Si PV modules making part of a roof in a building or hanging outside windows with various inclinations were measured with respect to the Intensity of the solar radiation on them under various environmental conditions. A relationship coefficient $f$ was provided whose values are compared to those from a $\mathrm{PV}$ array operating in a free standing mode on a terrace. A theoretical model to predict $f$ was elaborated. According to the analysis, the coefficient $f$ takes higher values for PV modules embedded on a roof compared to the free standing PV array. The wind effect is much stronger for the free standing PV than for any BIPV configuration, either the PV is part of the roof, or placed upon the roof, or is placed outside a window like a shadow hanger. The $f$ coefficient depends on various parameters such as angle of inclination, wind speed and direction, as well as solar radiation. For very low wind speeds the effect of the angle of inclination, $\beta$, of the PV module with respect to the horizontal on PV temperature is clear. As the wind speed increases, the heat transfer from the PV module shifts from natural flow to forced flow and this effect vanishes. The coefficient $f$ values range from almost $0.01 \mathrm{~m}^{20} \mathrm{C} / \mathrm{W}$ for free standing $\mathrm{PV}$ arrays at strong wind speeds, $\mathrm{v}_{\mathrm{W}}>7 \mathrm{~m} / \mathrm{s}$, up to around $0.05 \mathrm{~m}^{20} \mathrm{C} / \mathrm{W}$ for the case of flexible PV modules which make part of the roof in a BIPV system
\end{abstract}

Keywords: PV temperature, inclination, BIPV

PACS: $88.05 \mathrm{Bc}, 88.40 . \mathrm{H}-, 88.40 \mathrm{hj}, 88.40 \mathrm{mr}$

\section{INTRODUCTION}

Several research papers dealing with the temperature developed in the PV modules operating under field conditions have been published [1-5]. The development of temperature profiles in PV modules was well understood by studying the Energy Balance Equation as it concerns the power and heat produced in the PV module, as a response of the solar radiation on it [6-8]. PV modules are placed either on terraces in small fixed or sun-tracking configurations or they are integrated into the building shell. These configurations compose the so called BIPV family of systems [9]. In special building designs the PV modules are embedded in the facades or in the roofs. In the latter case, the PV modules are either placed at a small distance of $10 \mathrm{~cm}$ from the roof surface, or consist part or the whole roof. The existing research works so far have not studied in depth the effect of various BIPV configurations on the inter-relationship between the PV module temperature, $\mathrm{T}_{\mathrm{pv}}$ and the solar radiation on it, $\mathrm{I}_{\mathrm{T}}$. An approach was presented for PV systems in facades, [10], using the relationship in [4]. A wider analytic approach to this problem is presented in this paper for various BIPV configurations using the following relationship, taking also into account the ambient temperature, $\mathrm{T}_{\mathrm{a}}$, [7]:

$$
T_{P V}=T_{a}+f \cdot I_{T}
$$

The values the $f$ factor takes up for various types of BIPV installations were determined experimentally by using eq.(1). A theoretical estimation may be tried by a complete set of heat transfer and radiation expressions associated to the PV module energy balance equation. The ability to predict the $f$ values leads straightforward to the determination of the $\mathrm{T}_{\mathrm{pv}}$ and consequently to the estimation of the PV power performance dependent on the PV module temperature, inclination and environmental conditions, [7,9].

The PV module temperature $\mathrm{T}_{\mathrm{pv}}$ has an effect to the PV power, [6-11], and may be determined through eq.(1) from the $f$ values theoretically or experimentally produced in this paper.

International Conference of Computational Methods in Sciences and Engineering 2014 (ICCMSE 2014)

AIP Conf. Proc. 1618, 341-347 (2014); doi: 10.1063/1.4897744

(C) 2014 AIP Publishing LLC 978-0-7354-1255-2/\$30.00 


\section{THEORETICAL APPROACH}

Let a PV module inclined at an angle $\beta$ with respect to horizontal, $\mathrm{I}_{\mathrm{T}}$ the intensity of the solar radiation on it and $\eta_{\mathrm{pv}}$ its efficiency. A negligible part of the solar radiation is reflected from the PV module surface about 5-8\%. Hence, a solar energy rate equal to $\left(1-\eta_{\mathrm{pv}}\right)(\tau \alpha) \mathrm{I}_{\mathrm{T}} \mathrm{A}_{\mathrm{pv}}$ is dissipated into heat. This results to an increase of the PV temperature above the ambient $\mathrm{T}_{\mathrm{a}}$. The heat propagates to both sides of the module and eventually passes to the environment following all the possible modes from the front and back sides.

The energy balance equation for steady state conditions, shown in eq.(2), takes into account the solar radiation which reaches the PV module, the power produced, the heat losses due to conduction, convection, and the IR radiation to the environment.

$$
(\tau \alpha) \cdot I_{T}=\eta_{p v} \cdot(\tau \alpha) \cdot I_{T}+U_{L, f} \cdot\left(T_{p v, f}-T_{a}\right)+U_{L, b} \cdot\left(T_{p v, b}-T_{a}\right)
$$

$(\tau \alpha)$ is the transmission-absorption coefficient [9]. Its value in this case was around $0.90 . \mathrm{U}_{\mathrm{L}, \mathrm{f}}$ and $\mathrm{U}_{\mathrm{L}, \mathrm{b}}$ stand for the heat losses coefficients for the front and back sides, respectively, given by:

$$
U_{L, f}=h_{c, g-a}+h_{r, g-a} U_{L, b}=h_{c, b-a}+h_{r, b-a}
$$

$h_{c, g-a}$ and $h_{c, b-a}$ are the convection heat transfer coefficients for the front and back surface of the PV panel, respectively. They are determined for the heat transfer mode, forced or natural, laminar or turbulent at any geometry and environmental conditions, like wind velocity and its direction to the PV module and ambient temperature. A complete set of expressions to cover all these modes of heat transfer should be deployed $[12,13,14]$. Thus, a theoretical model was developed to predict $\mathrm{T}_{\mathrm{pv}}$ very effective for this case.

This set of equations is simplified by assuming at a first approximation that the heat generated into the PV cell, travels at equal rates towards both sides and that $\mathrm{h}_{\mathrm{c}, \mathrm{b}-\mathrm{a}}=\mathrm{h}_{\mathrm{c}, \mathrm{g}-\mathrm{a}}$. Setting $\mathrm{h}_{\mathrm{r}, \mathrm{g}-\mathrm{a}}=\mathrm{h}_{\mathrm{r}, \mathrm{b}-\mathrm{a}}=\mathrm{h}_{\mathrm{r}}$ and $\mathrm{T}_{\mathrm{pv}, \mathrm{f}}=\mathrm{T}_{\mathrm{pv}, \mathrm{b}}=\mathrm{T}_{\mathrm{pv}}$, a case not far from the reality is reached. Eq.(2) and eq.(3) combined give the approximate forms :

$$
\begin{aligned}
& \left(1-\eta_{p v}\right) \cdot(\tau \alpha) \cdot I_{T}=2 \cdot U_{L} \cdot\left(T_{p v}-T_{a}\right) \\
& T_{p v}=T_{a}+0.5 \cdot\left(1-\eta_{p v}\right) \cdot(\tau \alpha) \cdot I_{T} / U_{L}
\end{aligned}
$$

Introducing values for $\left(h_{c}\right)_{\text {free }}$ and $h_{r}$, at $T_{p v} 55^{\circ}-65^{\circ} \mathrm{C}$ and values for $\left(h_{c}\right)_{\text {forced }}$; for $\eta_{p v}=12 \%$ and for cases of PV modules in open air with a low wind velocity of less than $1 \mathrm{~m} / \mathrm{s}, \mathrm{U}_{\mathrm{L}}$ and $\mathrm{f}$ values are obtained. Eq.(5) in this case gives:

$$
T_{p v}=T_{a}+0.029\left(\mathrm{Km}^{2} / W\right) \cdot I_{T}
$$

For well protected areas, that is, in calm environment and relatively low PV module temperatures, $\mathrm{U}_{\mathrm{L}}$ may take a value down to $8-10 \mathrm{~W} / \mathrm{m}^{2} \mathrm{~K}$. Then, eq. (5) gives,

$$
T_{p v}=T_{a}+0.0425\left(\mathrm{Km}^{2} / W\right) \cdot I_{T}
$$

Even values up to $0.045-0.055 \mathrm{Km}^{2} / \mathrm{W}$ are obtained. This figure derived from the simple eq.(5) above provides a practical upper limit of the $f$ coefficient for the usual conditions.

For $\mathrm{U}_{\mathrm{L}}=15-18 \mathrm{~W} / \mathrm{m}^{2} \mathrm{~K}$, which is a case for a moderate wind velocity on the PV module, or when the air flow past the PV back surface gets turbulent, then, instead of $0.0425 \mathrm{~m}^{2} \mathrm{~K} / \mathrm{W}$ the coefficient decreases down to $0.020 \mathrm{~m}^{2} \mathrm{~K} / \mathrm{W}$, while for high wind velocity of more than $7 \mathrm{~m} / \mathrm{s}$ the coefficient reaches down to $0.01 \mathrm{~m}^{2} \mathrm{~K} / \mathrm{W}$, as estimated theoretically and determined experimentally. Based on the above,

$$
T_{p v}=T_{a}+f \cdot I_{T}
$$

where $f$ may be a function dependent on the solar radiation, the inclination angle, $\beta$, the type of heat convection; that is, natural or forced flow, the pattern of air flow past the PV panel, i.e. laminar or turbulent, the relative wind 
velocity direction with respect to the PV module surface and the type of the PV installation; that is, free standing PV, BIPV, concentration PV systems etc.

\section{EXPERIMENTAL RESULTS - DISCUSSION}

The $f$ values experimentally determined for the various PV types of installations are provided in figures below. Fig.1 shows the $\left(\mathrm{T}_{\mathrm{pv}}-\mathrm{T}_{\mathrm{a}}\right)$ vs $\mathrm{I}_{\mathrm{T}}$ for c-Si PV modules embedded on the solar roof, shown in Fig.2. The performance is monitored for 2 years. Regression analysis of the data provide $f$ values in the range of $0.038-0.047 \mathrm{Km}^{2} / \mathrm{W}$. In Fig.3, f values are provided for pc-Si PV modules either fixed or on a sun-tracker placed on a terrace. For low wind velocity for free standing systems $f$ decreases with the angle of inclination, $\beta$. Fig. 3 shows the dependence of $f$ on the wind velocity, as a parameter, whose values range from 0.015 for strong wind conditions up to $0.035 \mathrm{Km} / \mathrm{W}$ for low wind conditions. For a PV on a free environment or integrated into a façade or roof, $f$ decreases with increasing $\mathrm{v}_{\mathrm{w}}$. Figs. $4 \mathrm{a}$ and $4 \mathrm{~b}$ show $\left(\mathrm{T}_{\mathrm{pv}}-\mathrm{T}_{\mathrm{a}}\right)$ and the $f$ values for free standing PV modules fixed and sun-tracking on the building terrace for the month July under low wind conditions. It is clear that the fixed PV modules suffer from higher $f$ values compared to the sun-tracking ones. This is due to the changing inclination angle the PV modules in the sun-tracking systems get during the day. The same pattern holds for the other months. It is clear that the $\left(T_{p v}-T_{a}\right)$ changes with $\mathrm{I}_{\mathrm{T}}$ in a sub-linear way and that the $f$ coefficient is not constant. Even for the same geometry according to the theoretical model presented above, $f$ depends on the PV temperature, the solar radiation and the inclination for low wind velocity. That was verified with the theoretical model outlined before. The decrease of $f$ is bigger for free standing systems rather than for wind protected or systems where only one face is subjected to the wind. Fig. 5 shows PV modules hinged over a window and Fig. 6 gives the $f$ value to be determined by the slope of the straight lines. It is clear that the $f$ values decrease as $\beta$ increases. It is very interesting to realize that the slope of the curves for $\beta=45^{\circ}$ is the smallest one. This is due to the fact that the air flow past the PV module back side changes into turbulent. Figs. 7and 8 show the effect of the inclination angle to the $\mathrm{P}_{\mathrm{m}} \mathrm{vs}_{\mathrm{T} .}$, as it concerns wind protected areas. The same for the efficiency, $\eta_{\mathrm{pv}} \mathrm{vs} \mathrm{I}_{\mathrm{T}}$. It is clear in these figures that for low inclination angles the power losses due to low convection surface coefficient get higher. As the angle of inclination reaches $40^{\circ}-45^{\circ}$ the $f$ values lie in the range around 0.030 up to $0.036 \mathrm{Km}^{2} / \mathrm{W}$.

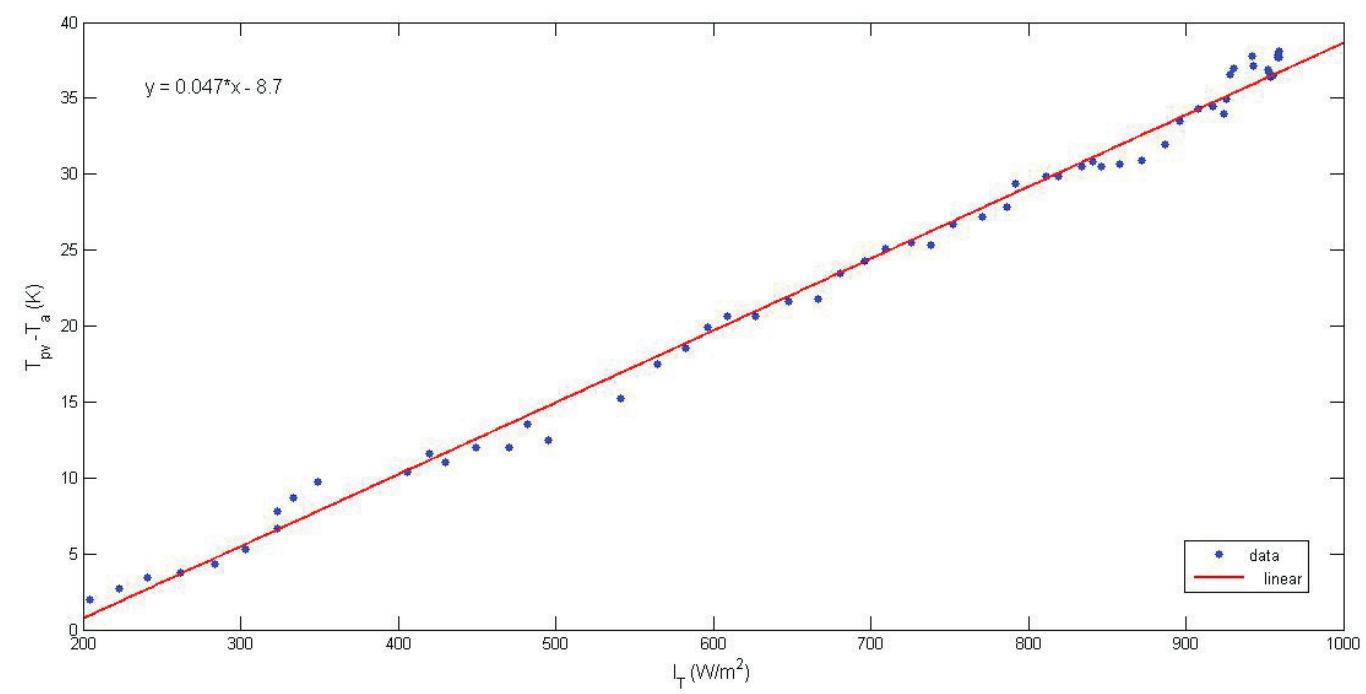

FIGURE 1. $\mathrm{T}_{\mathrm{pv}}-\mathrm{T}_{\mathrm{a}}$ vs $\mathrm{I}_{\mathrm{T}}$ for c-Si PV module embedded on the roof -BIPV 


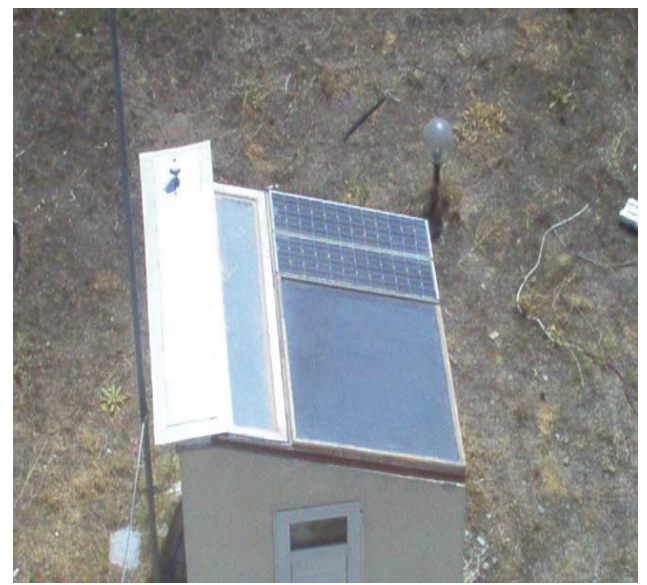

FIGURE 2. A test cell with a solar roof which consists of two c-Si PV panels while the rest of the roof operates as a solar collector.

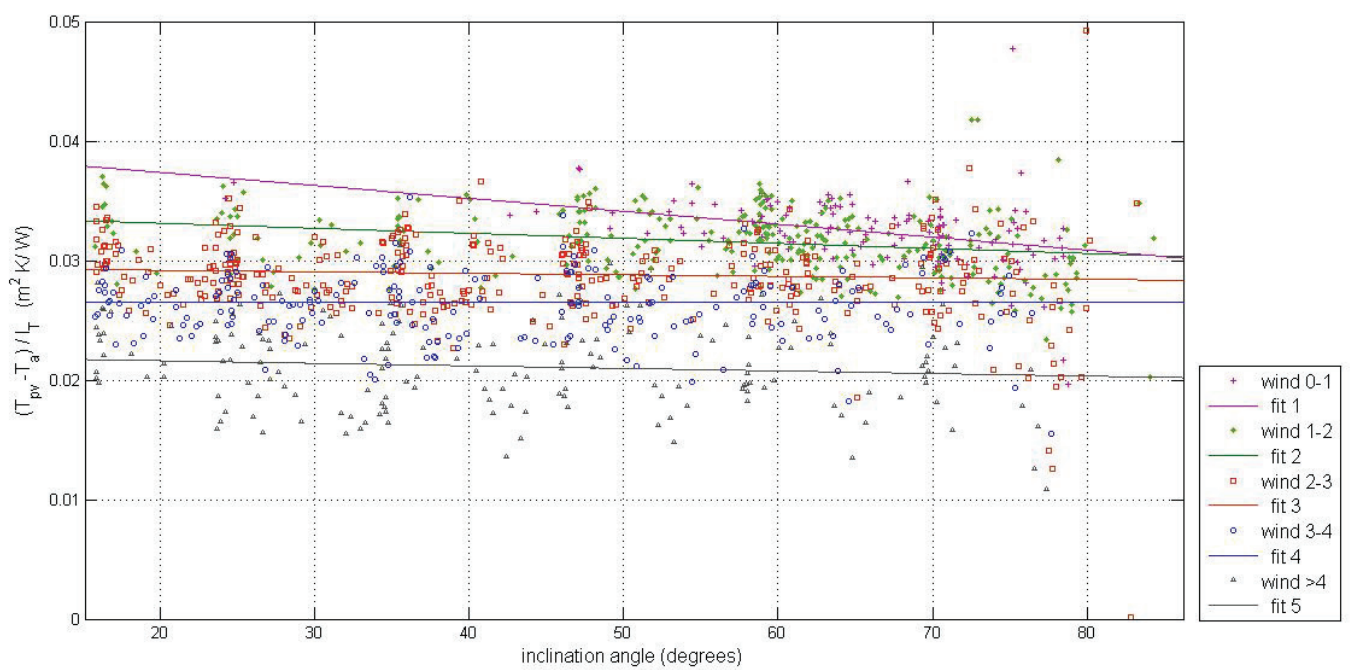

FIGURE 3. The f vs PV inclination angle for different groupings of wind velocities from $0.1 \mathrm{~m} / \mathrm{s}$ up to more than $4 \mathrm{~m} / \mathrm{s}$ for $\mathrm{pc}-\mathrm{Si}$ PV modules in free space.

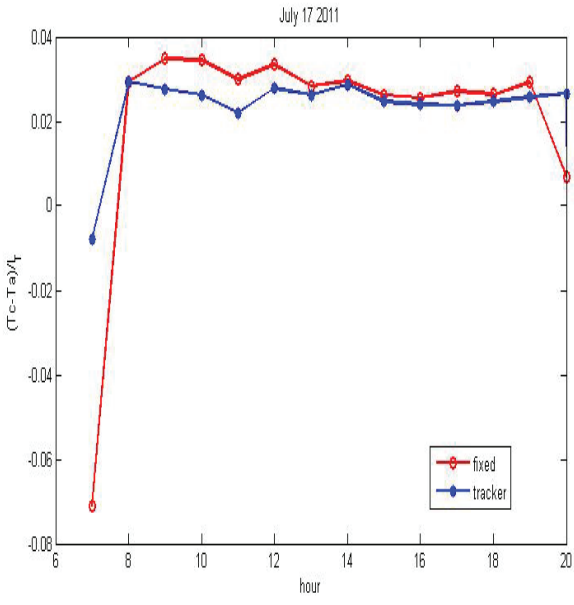

(a)

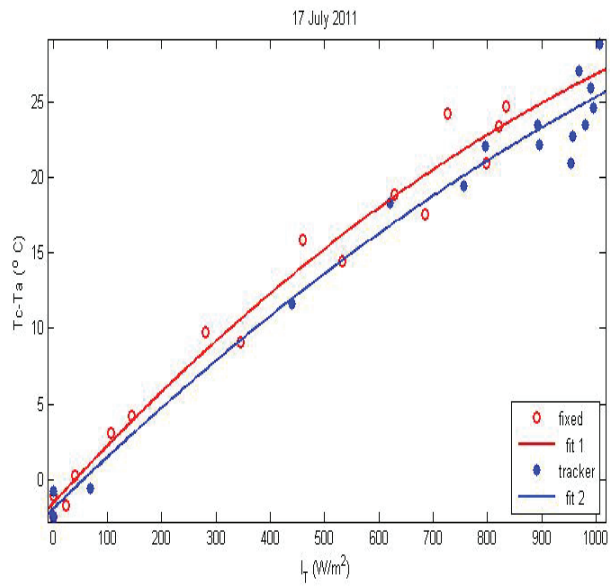

(b)

FIGURE 4. (a) The $f$ during the hours of the day and (b) $\left(T_{p v}-T_{a}\right)$ vs $I_{T}$, for free standing PV modules fixed and sun-tracking, 


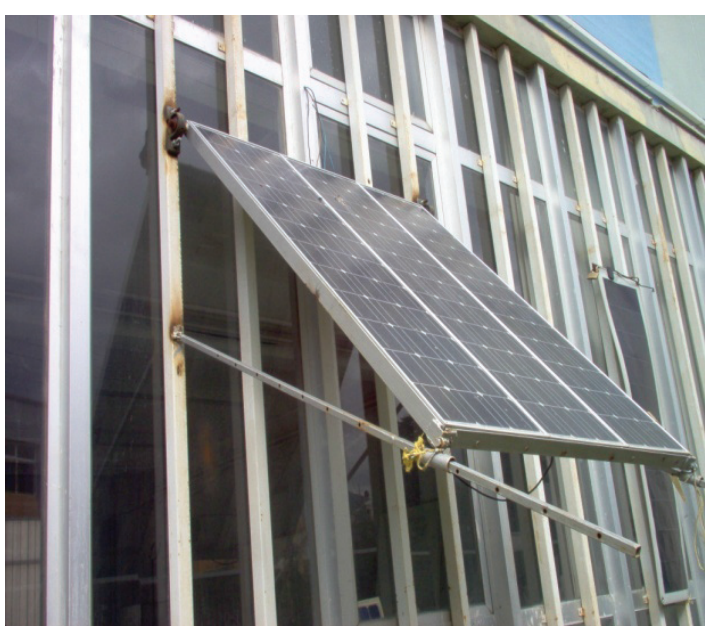

FIGURE 5. Three PV modules hinged on a window with an adjustment of inclination

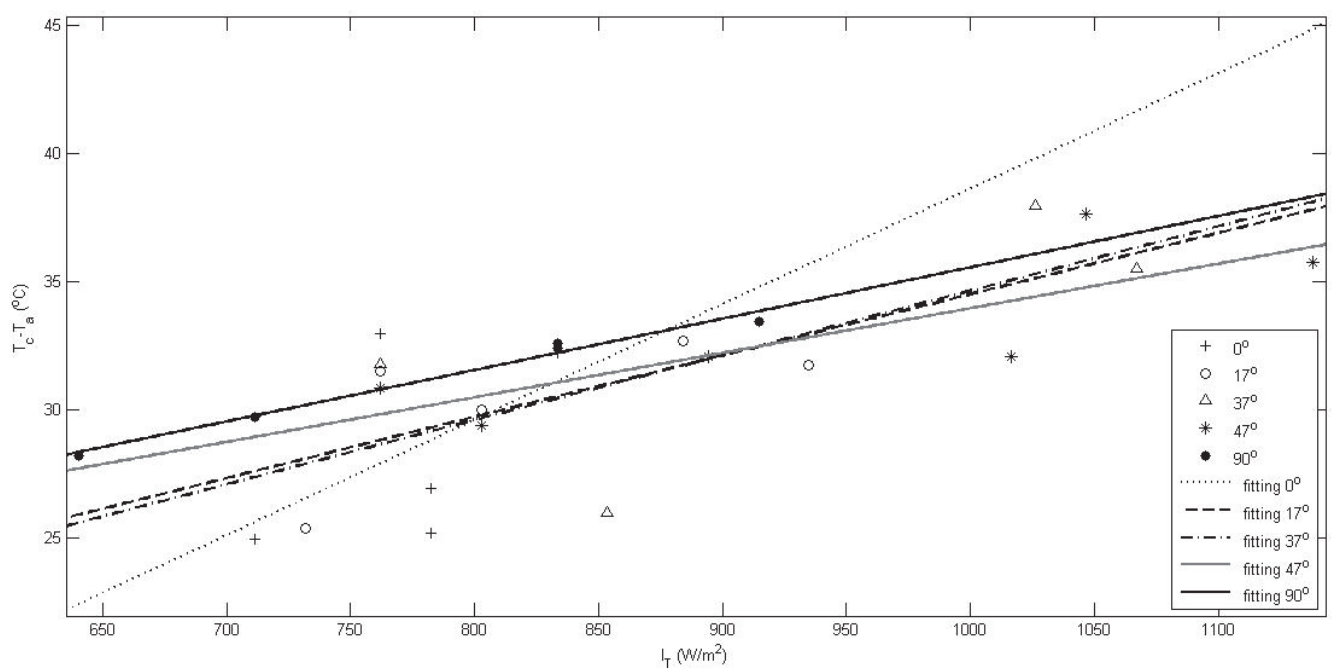

FIGURE 6. $\left(\mathrm{T}_{\mathrm{pv}}-\mathrm{T}_{\mathrm{a}}\right)$ vs $\mathrm{I}_{\mathrm{T}}$ for different PV inclination angles, for c-Si PV modules operating in free space -wind protected.

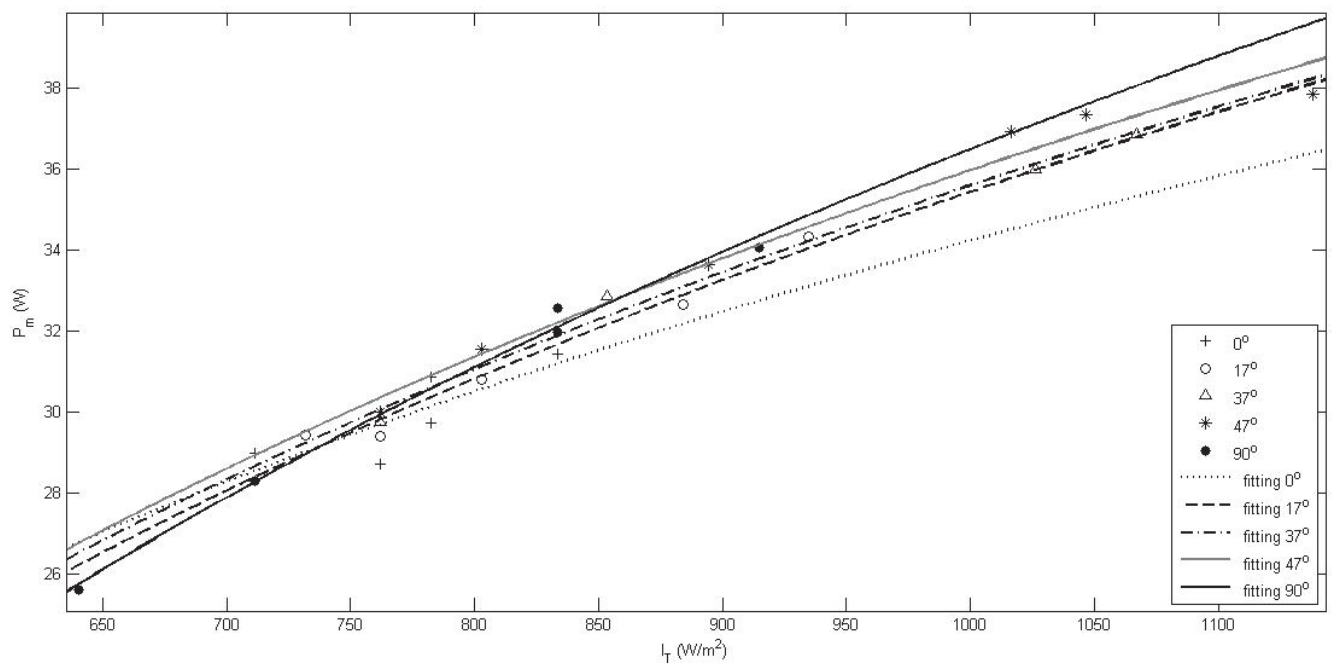

FIGURE 7. $\mathrm{P}_{\mathrm{m}} \mathrm{vs} \mathrm{I}_{\mathrm{T}}$ for different c-Si PV inclination angles, with the PV modules operating in free space -wind protected 


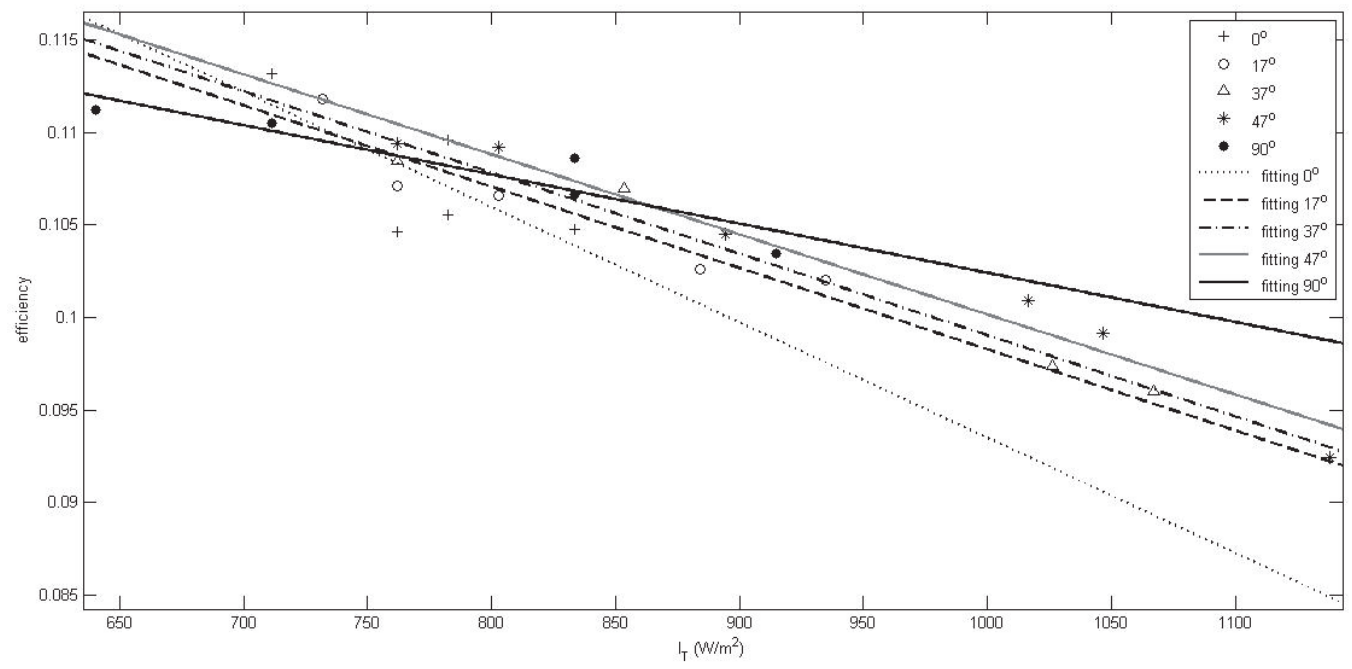

FIGURE 8. PV efficiency vs $I_{T}$ for different $P V$ inclination angles, for PV modules operating in free space -wind protected

\section{CONCLUSIONS}

The paper presents the experimentally determined PV module temperatures, $\mathrm{T}_{\mathrm{pv}}$ vs the solar radiation, $\mathrm{I}_{\mathrm{T}}$, on c$\mathrm{Si}$, pc-Si PV and a-Si modules for various BIPV installations. The relationship between $\mathrm{T}_{\mathrm{pv}}$ and $\mathrm{I}_{\mathrm{T}}$ was analysed theoretically and showed the dependence of the $f$ coefficient as it regards the wind velocity, $v_{w}$, the angle of inclination, $\beta$, and the configuration of the BIPV design, which affects indirectly the heat transfer from the PV module surface. The large volume data analysis showed that the $f$ value for various PV systems BIPV and standing ones for SMA installations at various latitudes reaches high values around $0.045-0.055 \mathrm{Km}^{2} / \mathrm{W}$ for PV modules embedded in the roof structure under low wind velocities, or just placed on the roof, as it occurs with flexible a-Si PV panels where $f$ value climbs according to the calculations made even more than $0.05 \mathrm{Km}^{2} / \mathrm{W}$. For wind velocities higher than $2-3 \mathrm{~m} / \mathrm{s}$ the $f$ value decreases and reaches down to $0.01 \mathrm{Km}^{2} / \mathrm{W}$ for free standing PV modules in a roof and wind speed $\mathrm{v}_{\mathrm{w}}$ higher than $7 \mathrm{~m} / \mathrm{s}$. Generally, in mild environmental conditions and for any latitude, $f$ values as expected lie within a margin of $[0.030 \pm 0.006] \mathrm{Km}^{2} / \mathrm{W}$. As the $f$ value increases for BIPV systems where the modules consist part of the building structure it is necessary to attach into the BIPV structure a cooling mechanism with permits or enhances the flow of coolant either air or fluid operating in a heat exchanger mode to extract heat from the modules to finally decrease the $f$ value. The estimation of $f$ makes able to predict the $\mathrm{T}_{\mathrm{pv}}$ and therefore to estimate in advance the PV power output to be delivered. This part is planned as further work.

\section{ACKNOWLEDGMENTS}

This paper dealing with the power performance of PV modules integrated into buildings is part of a research project entitled 'Development of innovative nanotechnology-based sustainable solutions for energy efficient buildings -EFFICONS' under LEAD ERA - FP7 and the operational programme of Western Greece Peloponnese and Ionian islands 2007-2013. The authors acknowledge the financial support of the project co-funded by the European Union -European Regional Development Fund and National Resources (NSRF 2007-2013).

\section{REFERENCES}

1. K. Emery et al, Proc.of $25^{\text {th }}$ IEEE PV specialist conference, Washington, USA, 13-19 May 1996, pp. 1275-1278

2. A.R. Wilshaw, J.R. Bates, N.M. Pearsall, Proc.of Eurosun `96, Munich, Germany, 1996, pp. 940-944

3. E.E. van Dyk et al, S. Afr. J. Sci 96, 198-200 (2000).

4. D.L. King et al, Sandia National Laboratories (2003).

5. A.R. Gxasheka, E.E. van Dyk, E.L. Meyer, Renewable Energy 30, 611-620 (2005).

6. Mattei M. et al., Renewable Energy 31, 553-567 (2006).

7. S.Kaplanis E.Kaplani P. Wolf, Proc. of WREC X, Glagow, 2008. 
8. G.M. Tina, R. Abate, Proc. 14th IEEE Mediterranean Electrotechnical Conference, 2008.

9. S.Kaplanis, E.Kaplani, Renewable Energy Systems: Theory, Innovations and Intelligent Applications, N.Y.: NOVA Science Publishers, 2013.

10. V. Benda, Proc. of Inno Week 2013, 30.06-08.07.2013, Patra, Greece, ISBN 978-969-7801-24-1

11. E. Radziemska, Renewable Energy 28, 1-12(2003).

12. F. P. Incropera, D.P. DeWitt, Introduction to heat transfer, John Wiley\&Sons, 1996

13. A.A. Kendouch, International Journal of Thermal Sciences, 48, 188-194 (2009).

14. B. Moshfegh, M. Sandberg, Renewable Sustainable Energy Rev 2, 287-301 (1998). 